\title{
A Heat Pump-Based Multi-source Renewable Energy System for the Building Air Conditioning: The IDEAS Project Experience
}

\author{
Silvia Cesari ${ }^{1}$, Alessia Natali ${ }^{1}$, Barbara Larwa ${ }^{1}$, Eleonora Baccega ${ }^{1}$, Micol Boschetti $^{1}$, Elena Mainardi ${ }^{3}$, Marco \\ Cavazzuti $^{*}$, Agostino Piazzi ${ }^{3}$, Giulio Mangherini ${ }^{2}$, Donato Vincenzi ${ }^{2,3}$, Michele Bottarelli ${ }^{1}$ \\ ${ }^{1}$ Department of Architecture, Università degli Studi di Ferrara, Via Ghiara 32, 44121 Ferrara, Italy \\ ${ }^{2}$ Department of Physics, Università degli Studi di Ferrara, Via Saragat 1, 44122 Ferrara, Italy \\ ${ }^{3}$ CFR - Consorzio Futuro in Ricerca, Via Saragat 1, 44122 Ferrara, Italy
}

Corresponding Author Email: marco.cavazzuti@unife.it

https://doi.org/10.18280/ti-ijes.650102

Received: 15 December 2020

Accepted: 26 February 2021

\section{Keywords:}

HVAC system, phase change materials, hybrid PV panels, radiant floor, renewable energy, shallow ground heat exchangers

\begin{abstract}
The current paper presents the state-of-the-art of the ongoing IDEAS research project, funded under the Horizon 2020 EU framework programme. The project involves fourteen partners from six European countries and proposes a multi-source cost-effective renewable energy system for the decarbonisation of the building envelope. The system features a radiant floor fed by a heat pump for the building thermal management. The heat pump can exploit sun, air, and/or ground as thermal sources through the use of photovoltaic/thermal solar panels, air heat exchangers, and shallow ground flat-panel heat exchangers. Thermal energy storage is achieved by means of phase change materials spread along several system components, such as: radiant floor to increase its thermal inertia, solar panels for cooling purposes, ground to enhance soil thermal capacity. Within the project framework, a smallscale building, featuring a plethora of sensors for test purposes, and two large-scale buildings are meant to be equipped with the renewable energy system proposed. The smallscale building is currently in operation, and the first results are discussed in the present work. Preliminary data suggest that while multi-source systems coupled with heat pumps are particularly effective, it is complex to obtain suitable thermal energy storages on urban scale.
\end{abstract}

\section{INTRODUCTION}

Buildings play a significant role in the global energy balance. Typically, they account for $20-30 \%$ of the total primary energy requirements of industrialised countries, while this share rises to $40 \%$ in the European Union (EU) [1]. Buildings sector energy intensity (in terms of final energy per square metre) globally fell by $1.3 \%$ per year between 2010 and 2014 thanks to the continued adoption and enforcement of building energy codes and efficiency standards. Yet, progress has not been fast enough to offset the growth in floor area (3\% per year globally) and the increasing demand for energy services in buildings [2]. A wider deployment of renewable energy in buildings becomes thus important to achieve EU's greenhouse gas emissions targets, which are set to $40 \%$ reduction by 2030, compared to 1990 levels, with at least a $27 \%$ share of renewable energy [3].

Energy requirements in buildings are primarily related to air conditioning and electricity needs, while the exploitation of renewable energy also poses the issue of energy storage. The integration of devices able to efficiently exploit different renewable energy sources and to store the thermal energy when needed offers an interesting solution to the everincreasing demand for space heating/cooling which has drawn the attention of researchers, and towards which the EU has devoted ample spaces in the Horizon 2020 and in the previous framework programmes for research.

Particular attention has been given to solar energy with projects proposing means for increasing the solar panel efficiency (EPHOCELL [4], PEDAL [5]), or for developing photovoltaic trigeneration systems based on heat pumps (TRIHP [6]), or solar/biomass hybrid systems (Hybrid BioVGE [7], SolBioRev [8]). Also ground heat exchangers have been addressed (GEO4CIVHIC [9]), as well as solutions for integrated renewable energy systems (RES) aiming at carbonneutral buildings (MAKING-CITY [10], RE-Cognition [11], RES4BUILD [12]). Other relevant topics which have been addressed are the thermal energy storage (TES) in buildings (i-STUTE [13], INPATH TES [14], SWS-Heating [15]), and the exploitation of phase change materials (PCMs) for storage purpose (TESSe2b [16], NPMSSES [17], EffiBUILDING [18]).

These topics are largely echoed in the literature. Among the means for increasing the solar panel efficiency we find the use of compound parabolic concentrators [19, 20], or luminescent dyes able to downshift ultraviolet solar wavelength to the visible range where solar cells work best [21, 22]. Concerning ground heat exchangers there is a renovate interest towards less expensive yet reasonably efficient shallow ground applications [23, 24], whereas integrated multi-source RES are dealt with in $[25,26]$. The use of PCMs in buildings meets several possible applications, such as their adoption in dedicated storage units [27], or in order to enhance the ground thermal capacity [28], the thermal inertia in radiant floors [29], or for thermal storage in photovoltaic systems [30].

Most of these solutions find application in the IDEAS 
project (novel building Integration Designs for increased Efficiencies in Advanced climatically tuneable renewable energy Systems) which is funded under the Horizon 2020 EU framework programme. The project proposes an innovative building-integrated multi-source RES aiming at a costeffective generation of electricity, heating, and cooling optimised for multi-family, public, or commercial buildings, under different climatic conditions. The system will provide renewable energy to the building, potentially cutting $\mathrm{CO}_{2}$ emissions up to $100 \%$.

The consortium shows a multidisciplinary knowledge profile covering all technical, techno-economic, and socioeconomic aspects of the project. It includes companies, laboratories, research institutes, non-governmental organisations, local authorities, and universities with specific expertise in the field of solar and renewable energy, thermal energy storage and PCMs, heat pumps, intelligent demandside management (DSM) and system control, user engagement. In details, the partners involved include: Trinity College Dublin (coordinator), Mayo County Council, Energy CoOperatives Ireland Ltd, Power Capital Renewable Energy Ltd, and APK Architects \& Engineers Ltd in Ireland, Ulster University, Phase Change Materials Products Ltd, and LF Fasthouse in the United Kingdom, Università degli Studi di Ferrara and Università degli Studi di Cagliari from Italy, Laboratório Nacional de Energia e Geologia IP and Associação Portuguesa das Empresas do Sector Fotovoltaico from Portugal, Acondicionamento Tarrasense Associacion from Spain, and Institut Mihajlo Pupin from Serbia.

Within the IDEAS project framework, the proposed RES has been installed on a small-scale building located in Ferrara (Italy) for test purposes and will be installed in the near future in two additional real-scale buildings, one in Ferrara, the other in Mayo County (Ireland).

The current work presents the state-of-the-art of the smallscale plant, which has been operating since August 2020, and discusses the first results collected so far.

\section{METHODOLOGY}

The aim of IDEAS project is to create a novel low-cost building integrated RES maximising the output and tuneable for different climatic conditions. Three renewable energy sources are herein exploited: sun, air, and ground.

Solar energy is captured with increased efficiency photovoltaic/thermal (PV/T) solar panels featuring luminescent dyes and quantum dots for solar wavelength downshifting. Compound parabolic concentrators, specifically designed for either roof or façade $\mathrm{PV} / \mathrm{T}$ installation, are used to increase the solar radiation intensity hitting the panel. The $\mathrm{PV} / \mathrm{T}$ efficiency is further increased by a proper thermal management of the cells through the use of PCMs, and a passive biomimetic heat transfer mechanism for heat storage and discharge. Air energy is collected with an ordinary air/water heat exchanger, while ground energy through shallow ground flat-panel heat exchangers. Through the panels, ground can also be used as a storage for the thermal energy in excess, and to this purpose it is integrated with PCMs in the neighbouring areas of the panel.

An electrically driven multi-source water-to-water heat pump uses the main energy sources at building scale to provide the required heating/cooling input to an integrated underfloor hydronic radiant system and to manage the TES. The thermal capacity of the radiant floor is enhanced once again with the addition of PCMs to increase its thermal inertia.

Artificial intelligence (AI) control techniques maximise the RES performance in view of the electrical, heating, and cooling self-sufficiency of the building. The technology will be tuned for optimal DSM in residential, commercial, and public buildings.

Figure 1 illustrates IDEAS concept schematically.

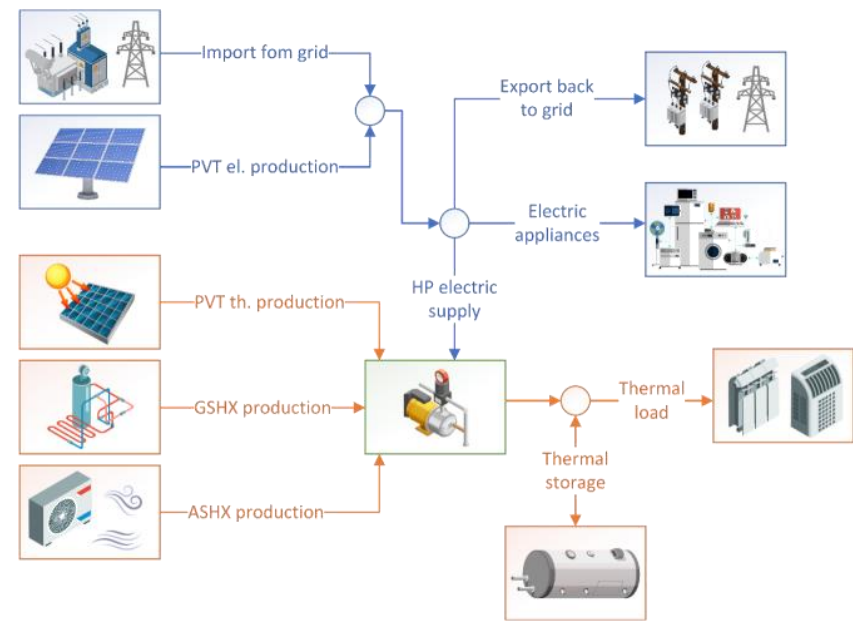

Figure 1. Scheme of the IDEAS RES (resources from freepik.com)

The installation of the IDEAS RES is at first planned on a small-scale prototype building for validation purposes, then on two real-scale buildings. Currently, the small-scale installation has been completed and is being tested.

In summary, the project objectives can be summarised as follows:

- design novel luminescence downshifting layers for the solar panels using high quantum efficiency luminescent dyes and quantum dots to increase the capture of direct and diffuse solar radiation;

- design a building integrated compound parabolic concentrator for different climatic locations;

- design a heat sink utilising PCM as TES to capture the $\mathrm{PV} / \mathrm{T}$ waste heat, thus achieving higher efficiencies of the panel;

- integrate the different energy sources with a water-towater heat pump feeding the radiant floor through TESs;

- design an AI-based DSM control maximising the system performance in terms of increased energy selfsufficiency of the building;

- develop a planning tool offering an optimal sizing of the system and assessing its environmental and economic impact for application to different building types and climatic regions;

- $\quad$ engage with building owners to get their input on the design and modelling tools developed, and produce an installer guide explaining the system modes of operation;

- $\quad$ install the IDEAS RES in demonstrator buildings.

The project is subdivided into the following work packages (WP):

- WP1: luminescent downshifting layer and compound parabolic concentrator;

- WP2: thermal energy storage;

- WP3: heat pump and underfloor heating and cooling;

- WP4: system control and demand-side management; 
- WP5: demonstration and validation;

- WP6: user community engagement;

- WP7: techno-economic and life-cycle analysis;

- WP8: dissemination and exploitation;

- WP9: management.

In WP1 the luminescent downshifting layer and the compound parabolic concentrator are fabricated. The project goes beyond the current state-of-the-art in that it includes plasmonic emission enhancement within the fabricated layer.

In WP2 the use of PCMs throughout the system is investigated. Different kind of PCMs are evaluated in relation to their application to thermal storage, $\mathrm{PV} / \mathrm{T}$ thermal regulation, and radiant floor distribution. A proper heat sink design is also proposed to enhance the PV/T cell cooling.

WP3 analyses the integration of the heat pump with the underfloor heating/cooling system on one side, and with the heat sources on the other side through suitable TESs for smoothing the mismatch between thermal supply and demand. At building scale the TES is provided by the PCMs embedded in the radiant floor, while on the source side by the ground that can be exploited either as source or storage. Ground heat exchanger is given by a flat plate maximising the heat transfer area, installed 2 metres deep. The advantage of such a shallow ground application is that the soil as a source is yearly recharged by solar energy, thus avoiding any thermal drift. The work package includes the development of a parametric numerical model of the RES proposed, to be used as a design tool in order to assess the plant performance for different building energy labels, in different climatic zones, and for different system control strategies.

WP4 focuses on the DSM. It includes the development of a planning tool for the system sizing, and an automation/control unit for the optimal energy dispatch. The control unit is able to interface itself with a wide range of sensors and actuators through different communication protocols, and features optimisation techniques and multiple-criteria decision-making algorithms. AI techniques use the production and demand forecast in order to determine the optimal day-ahead scheduling of energy assets.

WP5 deals with the application of the IDEAS system to two real-scale buildings. Demonstration sites are chosen in different climatic regions: namely, Italy and Ireland.

WP6 aims at a socio-economic analysis to gain qualitative knowledge on possible drivers and barriers to the adoption of the IDEAS system through focus groups with potential users in order to estimate the potential market demand.

In WP7 investment and operational costs of full-sized systems are estimated in order to identify possible scaling effects. Life-cycle analysis devises scenarios to incorporate circular economy improvements, thus reducing the resource intensity of the RES.

In WP8 the dissemination and exploitation plan enables the access to stakeholders, community groups, installers, planners, architects, and building services engineers through updates and direct engagement using traditional media, website, newsletters, and social media.

Lastly, WP9 ensures regular meetings between the institutions involved, establishing an efficient partnership and a continuous communication flow.

IDEAS is an ambitious project with clear and specific goals in scientific, engineering, and societal engagement aspects. The suggested solutions improve the RES performance and presume a large body of research with a view to industrial application so as to allow easiness of implementation and cost- effectiveness of the system as a whole.

\section{STATE-OF-THE-ART OF THE SMALL-SCALE PLANT}

The tasks connected to WP3 include the design of a suitable intra-day/season TES and of the multi-source/sink energy subsystem and its numerical implementation in a TRNSYS model, the installation of the small-scale plant, the plant testing, and the encoding of preliminary control rules.

As mentioned, the small-scale plant (Figure 2), is already in operation and represents the core topic of the current work. The small plant does not fully comply with the goals of the IDEAS project with regard to WP1 and WP2 in that common commercial PV/T panels are installed without a specific heat sink for cell cooling. With regard to WP4 a simplified system control is implemented: the data currently being collected will aid in the development of a more refined DSM tool.

The main activities related to the plant consist in numerical simulations supporting particular plant design choices, the actual construction works for the set-up of the small-scale prototype, and its undergoing plant monitoring. These activities are briefly summarised in the following lines.

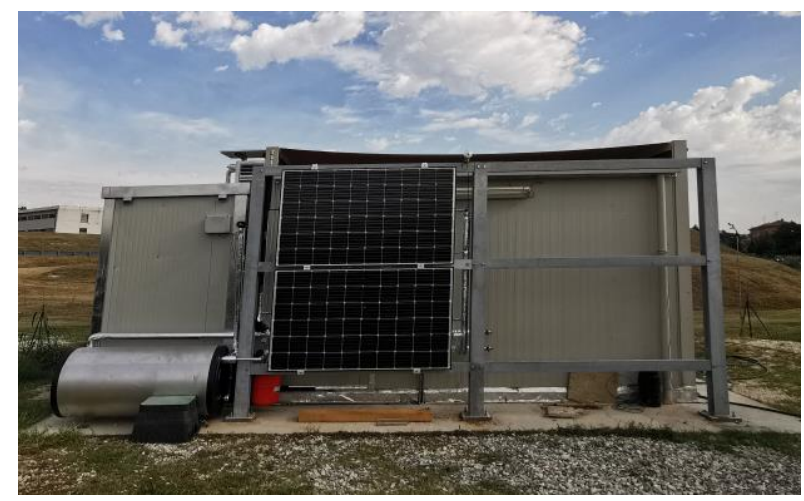

Figure 2. A view of the small-scale plant

\subsection{Numerical activities}

\subsubsection{TRNSYS model}

A parametric model replicating the small-scale plant (for a more detailed description of the plant refer to Section 3.2) has been developed in TRNSYS, a commercial software for the simulation of the transient energy behaviour in buildings. The model allows to easily and quickly predict the building energy performance in many scenarios such as different climate zones, system control rules, or construction solutions.

In this way, the model becomes an instrument for the plant layout optimisation and for the fine-tuning of its DSM tool, thus allowing to finally quantify the advantages that the IDEAS system may bring.

TRNSYS is a lumped-parameters software environment. It is based on blocks, called types, modelling the components of the system to be simulated. The various blocks are linked to each other so that they can exchange data. While the software comes with a large library of types, these are not necessarily enough to model some peculiar components proposed in the project, especially those integrated with PCMs. As such, some types had to be developed from scratch and then be validated, like the type simulating the flat-panel ground heat exchanger integrated with PCMs. Other types had to be provided with 
external files describing the specific thermal behaviour and properties of the PCMs, like the radiant floor. Finally, other types required specific performance maps that must be built either experimentally or from the component supplier technical data in order to operate, as for heat pump and support fan coils. All types had then to be tested and/or calibrated.

As mentioned above, among the in-house developed types there is the ground heat exchanger. The type implements the numerical model for flat-panel ground heat exchangers presented in [30], which allows the prediction of the temperature field as a function of time in the neighbourhood of the panel for a given heat flux time series at the panel surface, and ground surface and stable layer boundary temperatures. Compared to [31], the presence of the PCM is modelled as a layer interposed between the panel and the outer ground, thus decoupling the energy balance equation when the layer is active, i.e. PCM phase is changing. Inclusion of a PCM-to-panel heat transfer model allows the closure of the numerical problem. Figure 3(a) compares the experimental results with those obtained after the type calibration in terms of outlet temperature of the fluid crossing the flat-panel heat exchanger. The type is fed with the experimental inlet temperature as boundary condition.

Concerning TRNSYS model calibration, an important role is played by the thermal behaviour of the building envelope and its coupling to the underfloor heating/cooling system type. The whole thermal resistance chain going from the radiant floor to the outer environment passing through the building envelope must be tuned in order to account for possible thermal bridges. This operation is carried out iteratively up to when the building model is able to replicate at best a set of experimental results in terms of heat fluxes and temperatures both under summer and winter operating conditions. The results of the calibration for the cooling period are shown in Figure 3(b) in terms of room temperature and integral of the thermal power exchanged over a three-days period.

\subsubsection{COMSOL models}

Simulations in COMSOL Multiphysics are also employed in support of specific design choices or for validation purpose.

Concerning the radiant floor, the dedicated TRNSYS type used in the parametric model described above, being a nonstandard one, must at first be validated by means of unsteady $2 \mathrm{D}$ simulations. A portion of the floor was modelled with the two codes under the same boundary and operating conditions. A standard operation mode has been simulated over a time span of three days in a typical late winter condition where daily temperature fluctuations are large. A fourth day was then simulated in which the radiant floor was turned off after the PCM melted and the temperatures were monitored during solidification. A reasonable match was found between COMSOL and TRNSYS results.

Additional simulations were used to select the most suitable melting point for the PCMs to be used in the radiant floor. The energy demand of the test building was experimentally assessed under the hypothesis of $50 \%$ active heating/cooling time fraction and used to estimate the target floor surface heat flux the PCM should deliver on average when the radiant floor is turned off. This was compared with the numerical behaviour of the radiant floor investigated for different PCM melting temperatures, radiant floor set-ups (PCM layer positioned either above or below the water pipes), and supply water temperatures both in typical summer and winter conditions.

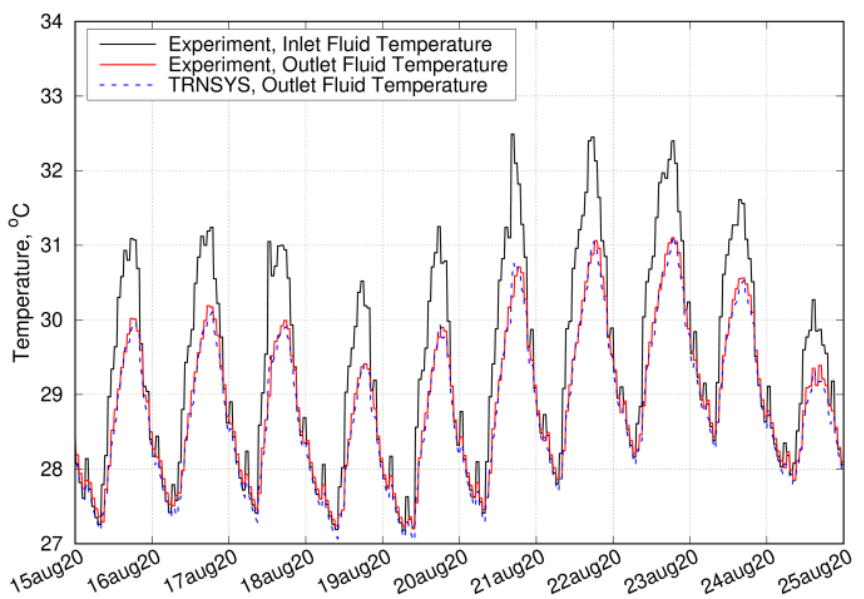

(a) Results of the ground heat exchanger type calibration

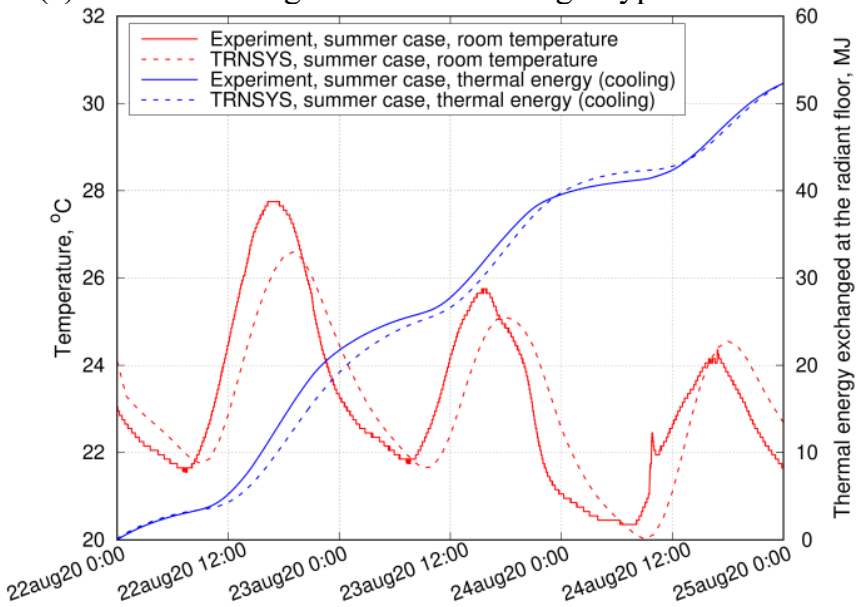

(b) Results of the building and radiant floor types calibration

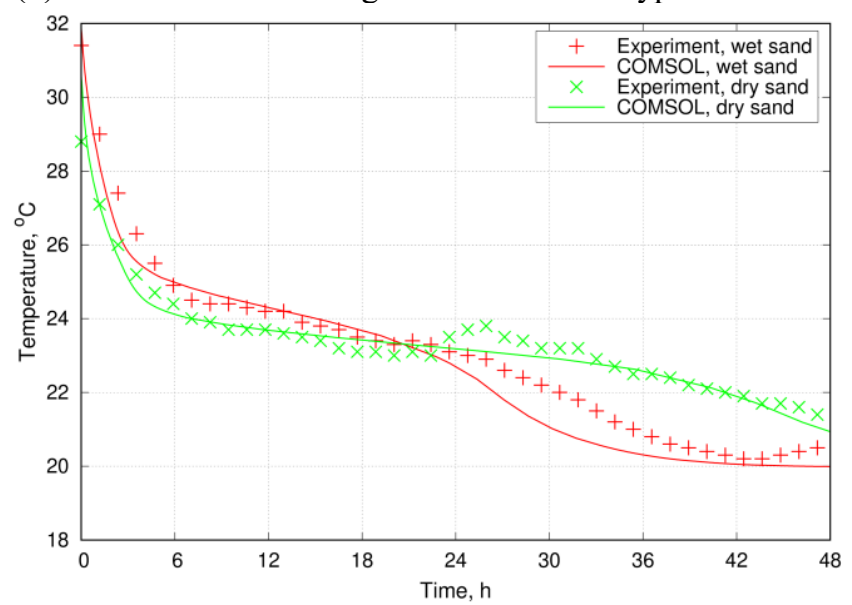

(c) Temporal changes of the radiant floor temperature for dry and wet conditions

Figure 3. Examples of numerical TRNSYS and COMSOL results vs experimental data 


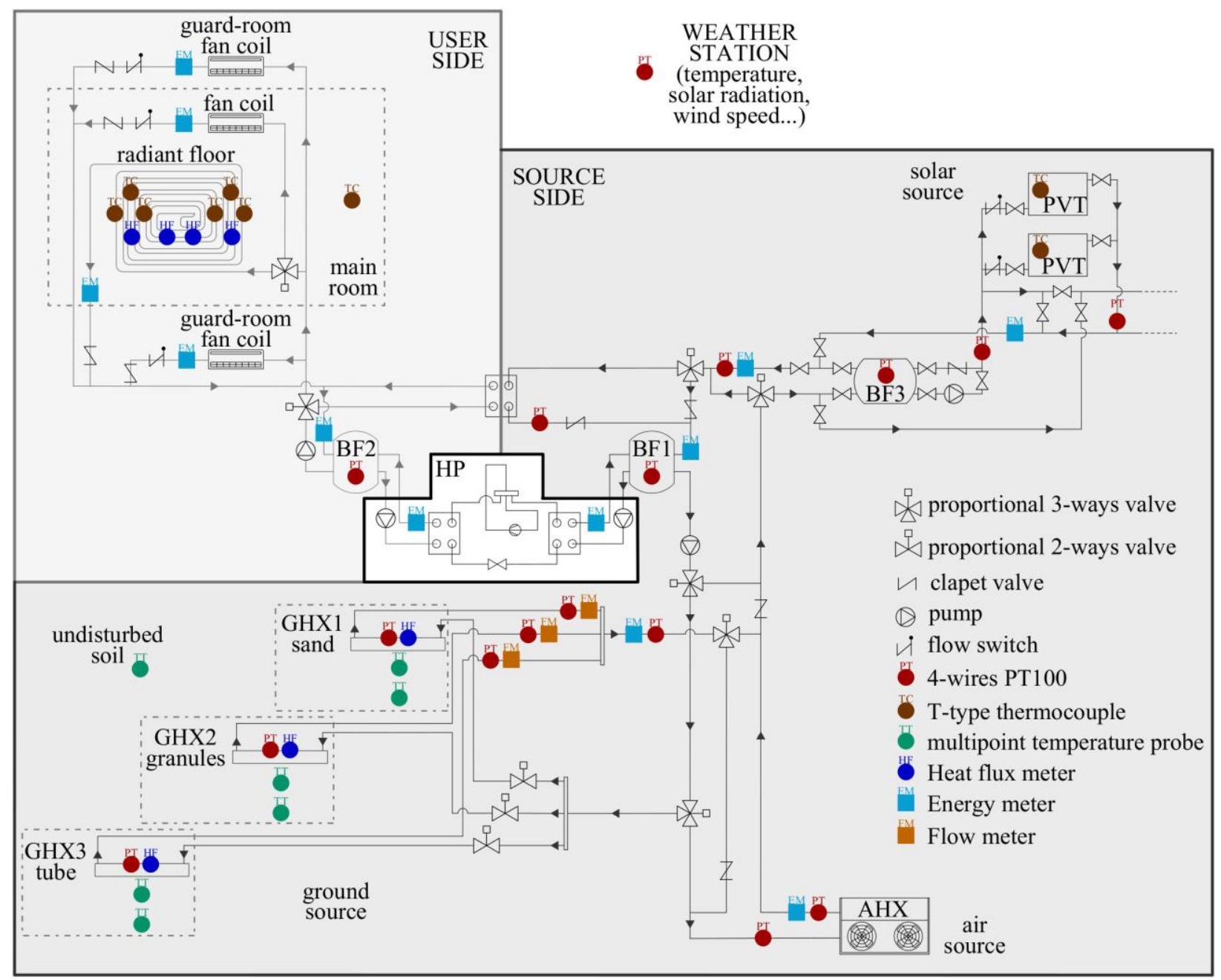

Figure 4. Detailed layout of the small-scale plant and of the installed sensors

The use of wet $v s$ dry sand in the radiant floor was also evaluated both experimentally and numerically (Figure 3(c)).

COMSOL simulations were finally used to evaluate the effects of the thermal inertia brought by the PCMs in the ground heat exchangers. This was needed to quantify the proper amount of each PCM type to be used with respect to the material cost $v s$ the benefit achieved. The benefit was evaluated in terms of reduced temperature drift observed in the ground either when the energy source is in use or when it is recovering after use. A second series of analyses dealing with the ground heat exchanger was made to discriminate in favour of the better PCM container shape to be used for the same amount of material. Possible choices provided by the supplier were parallelepiped and tube plastic containers. The choice fell on the latter as they allow a large surface area to be exposed to the flat panel (thus favouring energy storage), yet without thermally isolating too much the panel from the outer ground (thus favouring thermal recovery), and while granting a tighter installation in narrower trenches.

\subsection{Set-up}

Figure 4 shows a detailed layout of the small-scale plant. The plant is divided in two hydraulically separated loops, linked to the heap pump (HP in the central part of the figure): the user or building side (upper left), and the sources side (bottom right).

The water-to-water heat pump transfers heat between two water buffer tanks on the opposite loops. Automated proportional three-way diverting valves control the heat pump operation by switching between the building devices within the user loop, and between the available sources within the source loop.

On the user side the building is split into three spaces: the central test room ( $12 \mathrm{~m}^{2}$ floor surface, $32 \mathrm{~m}^{3}$ volume) equipped with the PCMs integrated hydronic radiant floor and supported at need by a fan coil, and two guard rooms placed on the east and the west sides ( $3 \mathrm{~m}^{2}$ floor surface, $8 \mathrm{~m}^{3}$ volume each), which are kept at a controlled temperature by fan coils.

The configuration of the installed radiant floor is illustrated in Figures 5(a) and 5(b). It consists of a thin laminate flooring as finishing, PCM encapsulated in thin high-density polyethylene containers - provided by PCM Products Ltd, partner of the IDEAS project - positioned above the screed with wet sand as filling material, a radiant insulation panel with studs in relief for laying and clamping water pipes. Hydrated salts PCMs with two different nominal melting points are employed: $21{ }^{\circ} \mathrm{C}$ for space cooling and $27{ }^{\circ} \mathrm{C}$ for space heating (always provided by PCM Products Ltd). Latent heat of fusion is equal to $220 \mathrm{~kJ} / \mathrm{kg}$ and $185 \mathrm{~kJ} / \mathrm{kg}$ respectively, for a total thermal storage capacity of approximately $50 \mathrm{MJ}$. This choice is made so in order to enhance the thermal inertia of the floor both in typical summer and winter operating conditions. The heating/cooling liquid flow to the rooms is controlled by three-way proportional valves. 


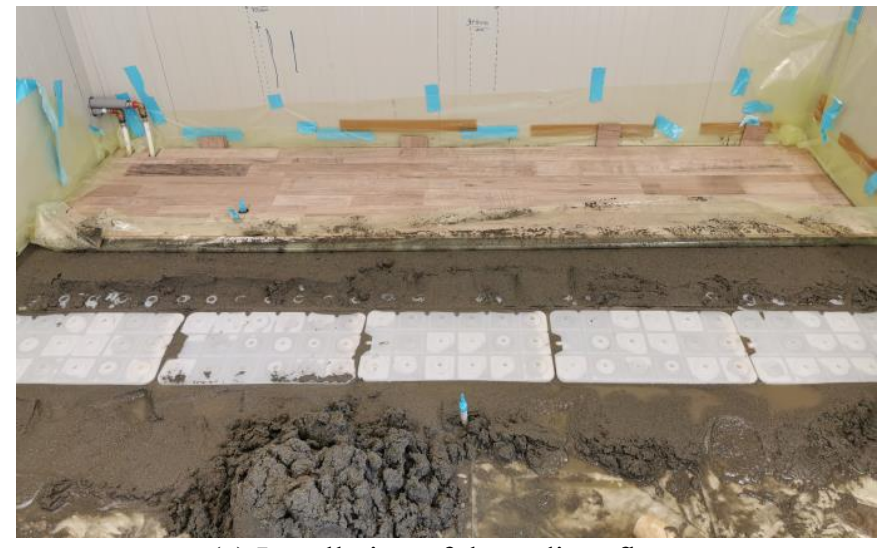

(a) Installation of the radiant floor

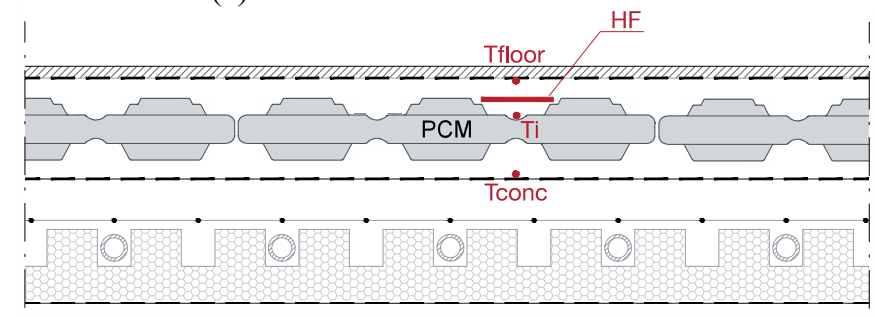

(b) Section of the radiant floor and sensors location

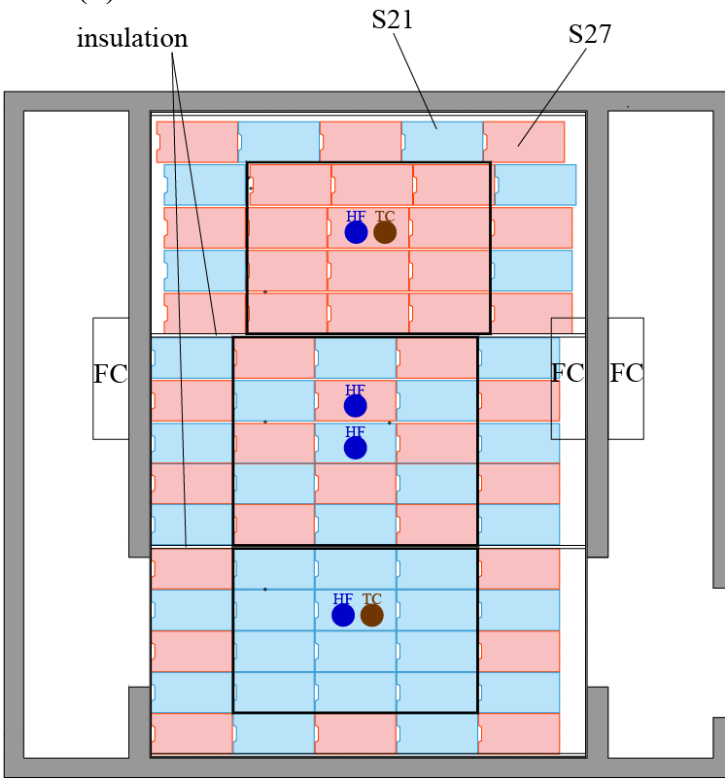

(c) PCMs distribution, temperature and heat flux sensors positioning in the radiant floor

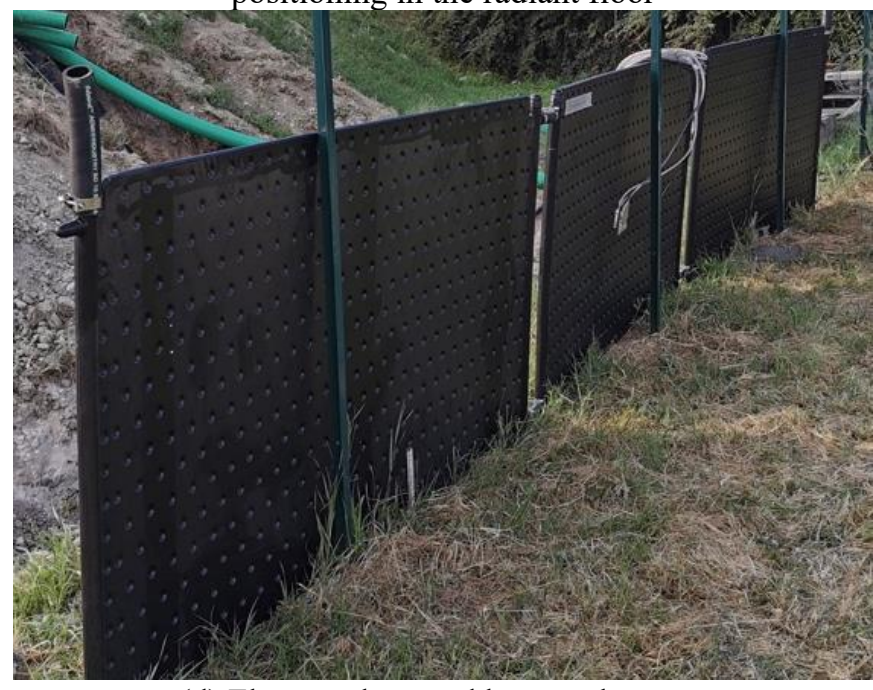

(d) Flat-panel ground heat exchangers

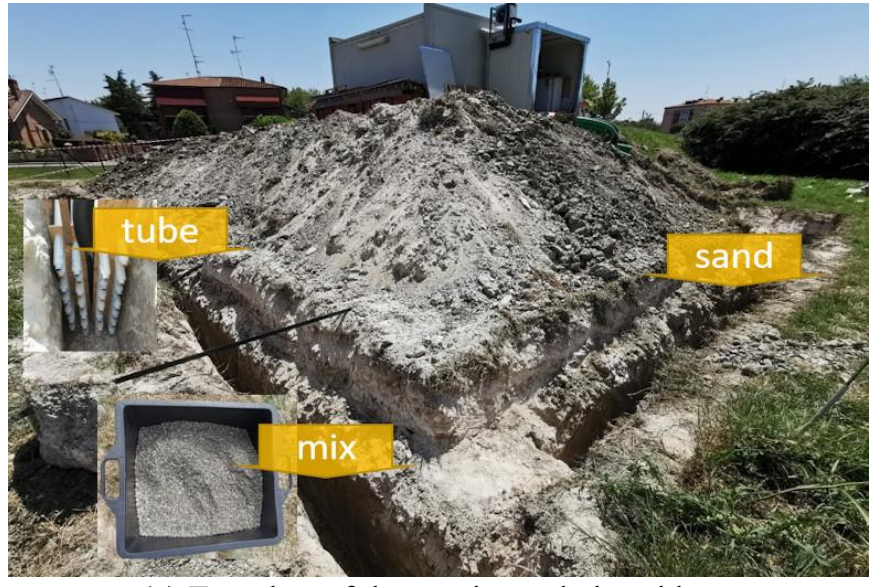

(e) Trenches of the geothermal closed loop

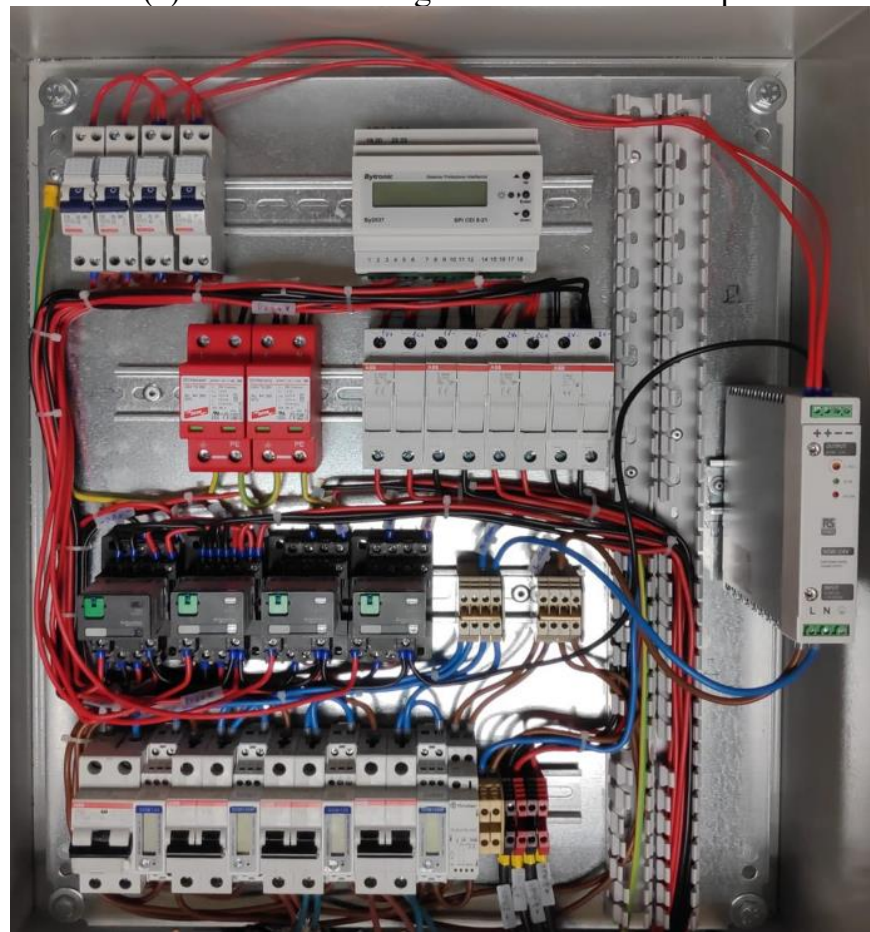

(f) Control panel of the PV/T modules providing connection to inverters, energy metering, and IV curve tracing

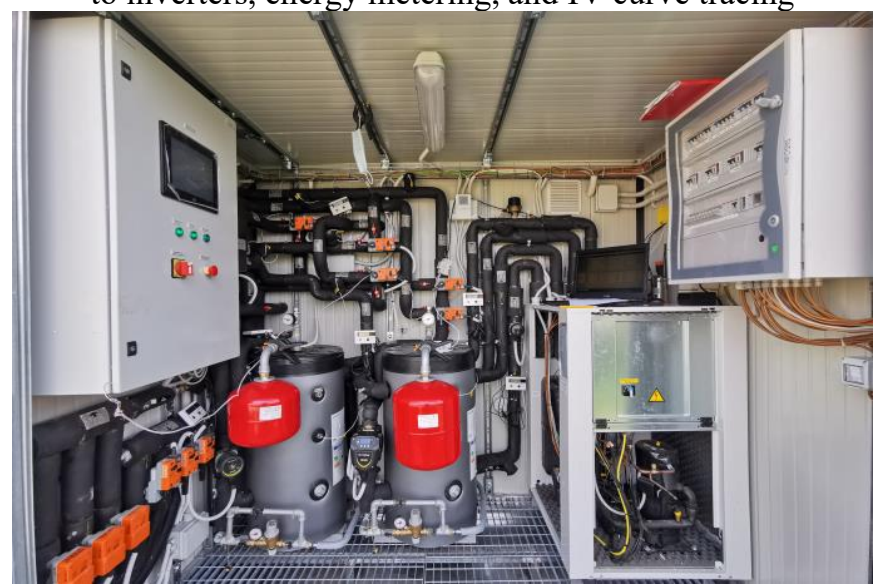

(g) Heat pump, piping, and PLC prefabricated container

Figure 5. Prototype plant construction at a glance

Figure 5(c) shows the distribution of the two different PCMs on the radiant floor surface (low-melting point PCM is represented in cyan, high-melting point PCM in pink), along with the positioning of temperature and heat flux sensors. 
On the sources side, for test purposes, three series of three flat-panel ground heat exchangers (each panel is $2 \mathrm{~m}$ long and has $4 \mathrm{~m}^{2}$ of active heat transfer area, see Figure 5(d)) are buried within sand-filled $0.4 \mathrm{~m}$ wide and $2.5 \mathrm{~m}$ deep trenches (Figure 5(e)): in one line hydrated salts as PCM encapsulated in cylindrical high-density polyethylene containers are installed in the terrain beside the panel, in another line paraffin granules that had been previously mixed directly with sand are used as backfilling material, while in the last series no PCM is added. Two PCMs with different melting points, namely, $8{ }^{\circ} \mathrm{C}$ and $27^{\circ} \mathrm{C}$ - provided by PCM Products Ltd - are used to grant thermal storage capacity both in winter and in summer operating conditions respectively. The total thermal capacity is around $50 \mathrm{MJ}$ (67\% due to the low-melting point PCM for winter, $33 \%$ due to the high-melting point PCM for summer). The three series can be operated either singularly or in parallel being regulated by automated two-way valves, and during the test phase will allow the comparison of the different solutions in terms of performance.

Through a dedicated circulator pump, the commercial PV/T panels are linked to a PCM-filled buffer tank for panel cooling and excess heat storage purposes. Once more, hydrated salts based PCMs are used, with two different melting points of $10^{\circ} \mathrm{C}$ and $32^{\circ} \mathrm{C}$. The total thermal capacity is about $30 \mathrm{MJ}$. The $\mathrm{PV} / \mathrm{T}$ panels are installed vertically on a steel structure on the south façade of the test building.

PV modules are provided with independent monitoring of the DC and AC parameters (Figure 5(f)). Each PV/T module is coupled with a four-wire connection to a relay (Zelio RPZF4 by Schneider Electric) providing the switchover between inverters and IV curve traces. Most of the time the PV/T modules are connected to two microinverters (Enphase IQ760-2-US) ensuring independent maximum power point tracking. The AC power is then measured with two AC meters with ModBus RTU interface. The power produced by the modules is then fed into the internal microgrid (heat pump, circulators, PLC, resistive heating elements). Periodically, each relay is switched to the IV curve tracer for the measurement of the IV characteristic and the maximum DC power provided by the modules. An additional indication of the DC power in operating conditions is provided by the inverters connected to an Enphase Envoy-S gateway. In case the power produced by the $\mathrm{PV} / \mathrm{T}$ modules is higher than the power drained by the internal microgrid, the excess power is dissipated by an AC load (APS 3A300-04).

The sources loop is completed by a commercial air source heat exchanger given by a standard tube and fins fan heater.

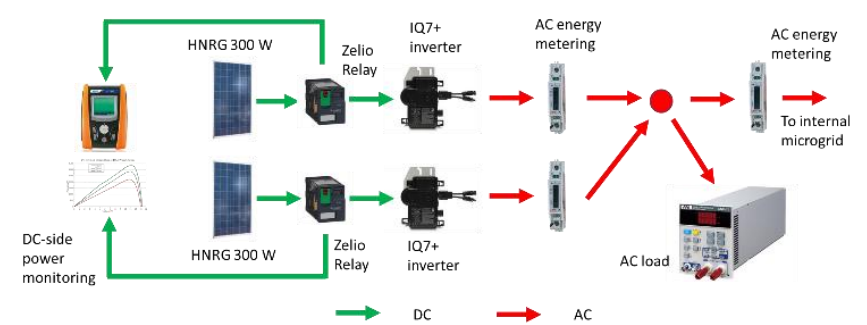

Figure 6. PV/T modules electrical connection diagram

A prefabricated container is installed next to the test building on its west side to provide space for the installation of the main part of the equipment (e.g. heat pump, buffer tanks, PLC), and for hydraulic and electrical piping (Figure 5(g)).

A twofold control system is developed: from one hand there are a proprietary programmable logic controller (PLC) and a touch screen human-machine interface (HMI) provided by one of the project partners, on the other hand a commercial solution based on a Visual C\# program acting both as control algorithm and operator interface. In the former, all the hardware is connected to the PLC that reads from sensors (e.g. weather station), equipment (heat pump, air heat exchanger, valves, and so on), dataloggers (Datataker), and controls the state of every connected device trying to optimise energy consumption on the basis of rules related to temperatures and sources usage. The latter is a quick temporary solution made necessary due to the COVID-19 pandemic preventing the foreign partner from visiting the installation site for the control system commissioning. In both control architectures three different communication protocols are used to connect the equipment to the controller: Modbus RTU (proportional valves, heat pump, weather station, air heat exchanger, electrical energy meters), Modbus TCP (Datataker), MeterBus (thermal energy meters). The three communication lines (Figure 7) run from the plant to the central controller, collecting data every minute and sending back commands with the same frequency. The large set of data collected is stored in a database for post-processing. Security circuit breakers allow the equipment to be disconnected from the powerline in case of unexpected events.

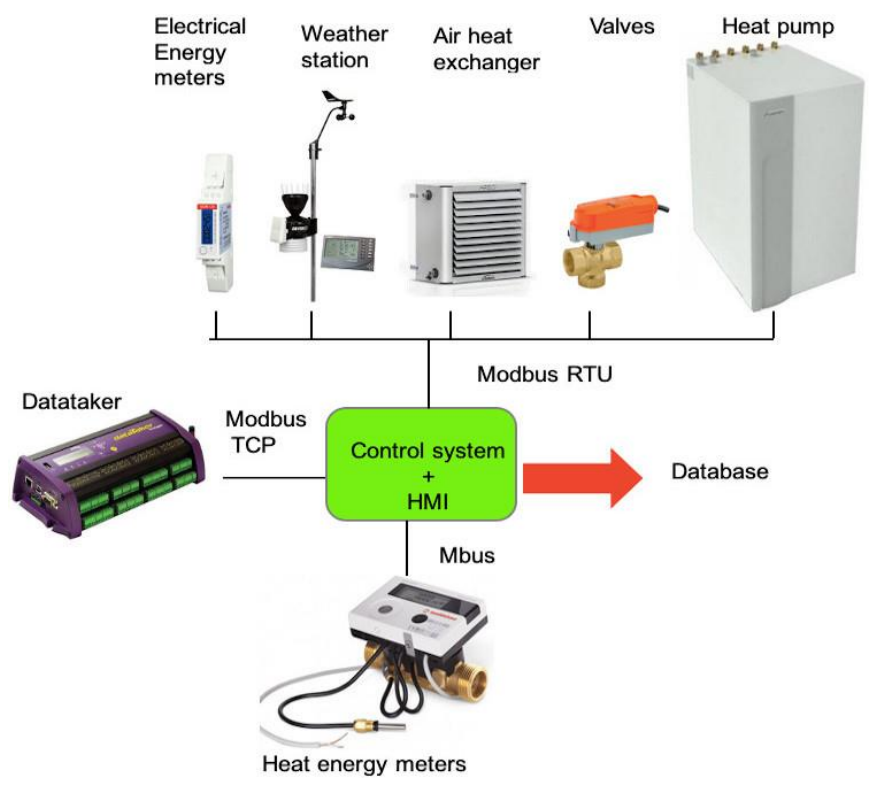

Figure 7. Control system and communication protocols

\subsection{Monitoring}

Monitored quantities include temperatures, relative humidity, mass flow rates, heat fluxes, electrical and thermal powers read at the various plant components or in the building rooms. Further, a weather station provides measurements for solar radiation, air pressure, outdoor temperature and relative humidity, wind direction and speed, and rain intensity. Overall, more than 60 quantities are constantly monitored through a large set of probes (see Figure 4) at regular customisable time intervals.

With regard to the hydraulic system, temperatures are read with four-wires metal-tip PT100 resistance temperature probes. Energy meters at the inlet and at the outlet of each component deliver instant and total mass flow rates and powers. Further, T-type thermocouples are used on the surface of the PV/T 
panels and between the layers of the radiant floor (Figure 5(c)), while a grid of multipoint TT digital probes are used in the soil at different spots around the ground heat exchangers (namely, $0.2 \mathrm{~m}$ and $1 \mathrm{~m}$ far from the panel, and $0.6 \mathrm{~m}, 1.2 \mathrm{~m}, 1.7 \mathrm{~m}$, $2.15 \mathrm{~m}, 2.6 \mathrm{~m}$, and $3.7 \mathrm{~m}$ deep from the ground surface). Heat flux meters are placed on the flat-panel ground heat exchangers and in the radiant floor.

The AC energy produced by the $\mathrm{PV} / \mathrm{T}$ panel inverters is measured and logged using a single-phase multi-function meter (RS Components SDM-120C) featuring ModBus protocol over RS485.

The DC power produced by each single module have been measured using the Enphase Envoy-S gateway and, periodically, disconnecting the modules from the inverters and tracing the IV using a I-V400 - SOLAR I-V curve tracer (Figure 8). The inverters kept the modules operating constantly at the point of maximum conversion efficiency. The time required for the switchover of the $\mathrm{PV} / \mathrm{T}$ modules connection and the IV curve tracing is just 6 seconds, so we can assume the temperature of the modules during the curve tracing is constant.

In the following, preliminary experimental results for the summer and the winter seasons are briefly discussed.

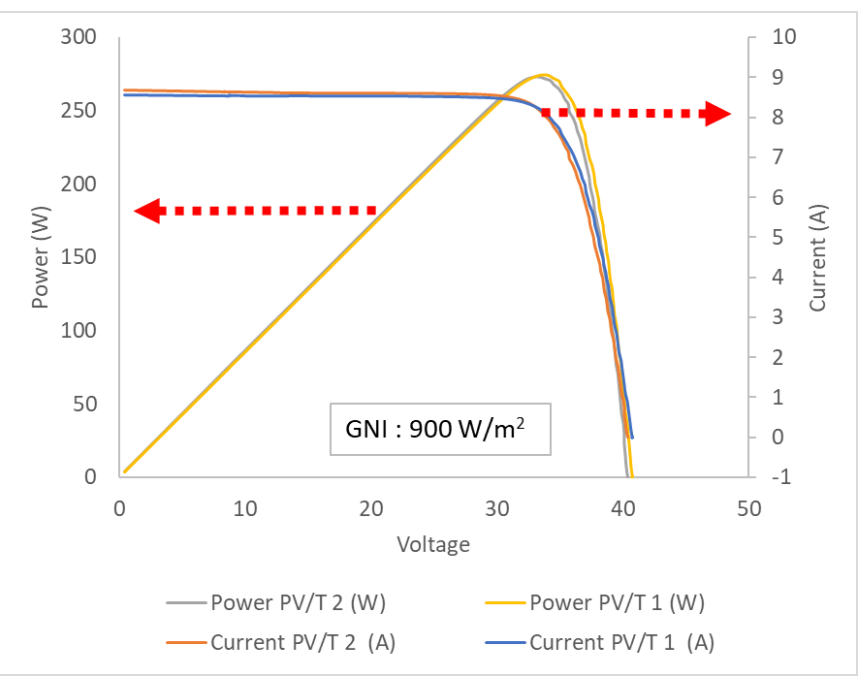

Figure 8. IV and PV curves of the modules under test with a global irradiance of $900 \mathrm{~W} / \mathrm{m}^{2}$

\subsubsection{Summer season}

In the radiant floor, temperature and heat flux sensors are placed above the PCM layer, both on top of the $21^{\circ} \mathrm{C}$ (T_S21 and HF_S21 in Figure 9(a)) and the $27^{\circ} \mathrm{C}$ (T_S27 and HF_S27) melting point materials. Temperature is further read on the slab surface and in the room. Figure 9(a) shows the trend of temperatures and heat fluxes over a two-day period early in September. Due to the low thermal insulation of the test building, the set-point temperature could not be granted by the radiant floor alone on the hottest hours of the day so that also the fan coil was used to support the cooling needs. When the radiant floor is operating (see the zigzag paths in the figure), the temperature above the S21 container is reduced more slowly compared to the S27 due to the phase change occurring. This is compliant with the thermal inertia of the floor that can mitigate temperature variations when the radiant floor is switched off.

Ground heat exchangers were primarily exploited during summertime due to the higher air temperature. Over a nearly two months period $750 \mathrm{kWh}$ of heat were injected in the ground. Maximum temperature in the trenches, though, did not exceed $28^{\circ} \mathrm{C}$. The preliminary data collected so far is insufficient to clearly discriminate the different thermal behaviour in the trenches, except for a different cooling rate of the ground, due to the increased thermal inertia, once the ground heat exchangers were switched off in September.

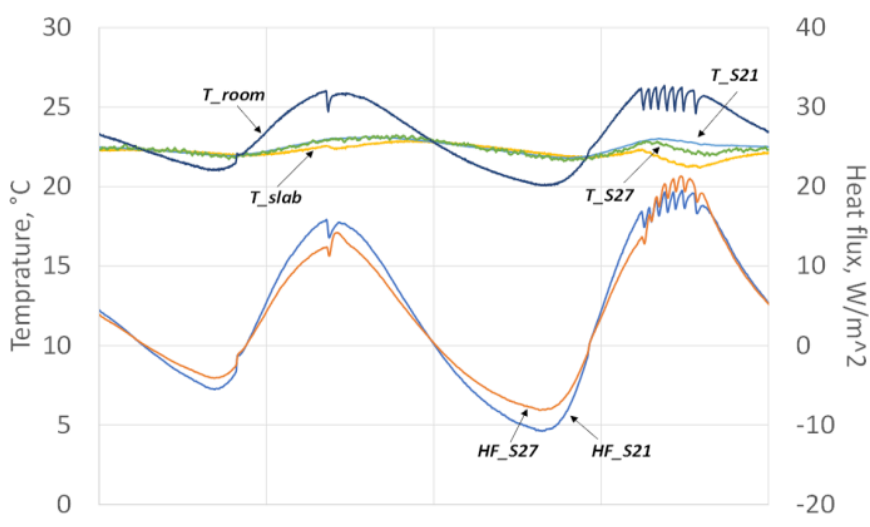

8/9/200:00 8/9/20 12:00 9/9/200:00 9/9/20 12:00 10/9/200:00 (a) PCM impact on the radiant floor

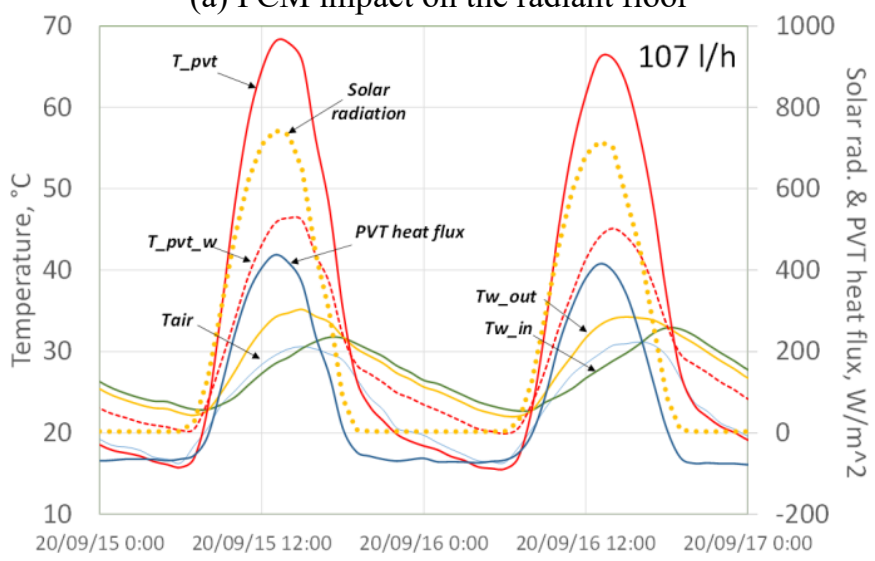

(b) Effects of $\mathrm{PV} / \mathrm{T}$ cooling

Figure 9. Summer season: radiant floor and PV/T preliminary experimental results

The effect of PV/T cooling is depicted in Figure 9(b). For test purposes, one of the two PV/T panels installed in the small-scale plant (marked with pvt_w in the figure) was cooled with a water flow from the PCM-filled tank, whereas the other panel (pvt) was not cooled over a two-day period in September. With water cooling, peak temperatures in the panel are reduced by over $20^{\circ} \mathrm{C}$. This suggests active PV/T cooling may bring reasonable improvements in terms of the panel efficiency, with the additional chance to store the thermal energy in excess.

\subsubsection{Winter season}

The winter testing season started early in November and is still ongoing. Given the system complexity, the progressive implementation of automation loops, and the need to investigate the behaviour of the different sub-systems, the plant was subject to specific forcing.

Among these the fact that the geothermal loop was the most exploited due to the undersizing of the air heater and the limited solar contribution. Figure 10(a) shows the soil temperature $1.7 \mathrm{~m}$ deep and $0.2 \mathrm{~m}$ far, i.e. at the trench border, from the second panel in each series. The figure also shows the temperature of a similar sensor located away from the geothermal loop, thus returning the undisturbed ground 
temperature as a term of comparison. In the figure, it is apparent how the ground heat exchanger series worked either individually or in parallel to other series at different times. The reported trends also show the significant speed in the recovery of the soil temperature once the geothermal loop exploitation is interrupted, being the undisturbed soil temperature recovered in approximately 20 day.

Figure 10(b) shows the temperature difference between the previous sensors and those placed at the same depth, but at a distance of $1 \mathrm{~m}$ from the flat panels, i.e. beyond the trench. To be noted the lower temperature difference (more than $1{ }^{\circ} \mathrm{C}$ less) measured in the hydrated salts tube container trench as a result of the PCM change of phase after the parallel exploitation of the three series carried out up to the beginning of December. On the contrary, paraffin granules trench behaves like the trench without PCM, whereas paraffin granules were expected to perform better than hydrated salts after preliminary laboratory tests. This aspect is currently under investigation and could be due to issues encountered during the first installation of the flat-panel heat exchangers where water leakages were experienced, and the installation had to be repeated by digging and filling the trench again.

Figures 10(c) and 10(d) show the system behaviour during a sudden drop in the ambient temperature due the Siberian High occasionally striking the Po valley with dry and cold winds in winter.

Figure 10(c) shows the temperature of the ambient air (T_air), of the heat transfer fluid at the PV/T panels (T_pvt) and at the geothermal loop ( $\mathrm{T}$ ghx) outlets, and within the buffer tank on the source side (T_wf). The automation has effectively controlled the proportional valves with respect to the different source temperatures. In fact, while the ground heat exchanger alone is exploited from dusk to dawn, the solar contribution allowed the tank to be refilled and the soil to be thermally regenerated during the warmer daytime hours. While the air temperature fluctuated between $-6^{\circ} \mathrm{C}$ and $+7^{\circ} \mathrm{C}$, the tank feeding the heat pump remained in the temperature range between $+3^{\circ} \mathrm{C}$ and $+8^{\circ} \mathrm{C}$.

This was made possible by a particularly clear sky and a high solar irradiation (Figure 10(d)) with peaks above 950 $\mathrm{W} / \mathrm{m}^{2}$ measured with a Hukseflux standard secondary pyranometer installed on a vertical plane. As a result, beside the thermal power captured, the electrical power production of the two PV/T panels reached a peak of $250 \mathrm{~W}$ per panel with an average efficiency around $16 \%$.

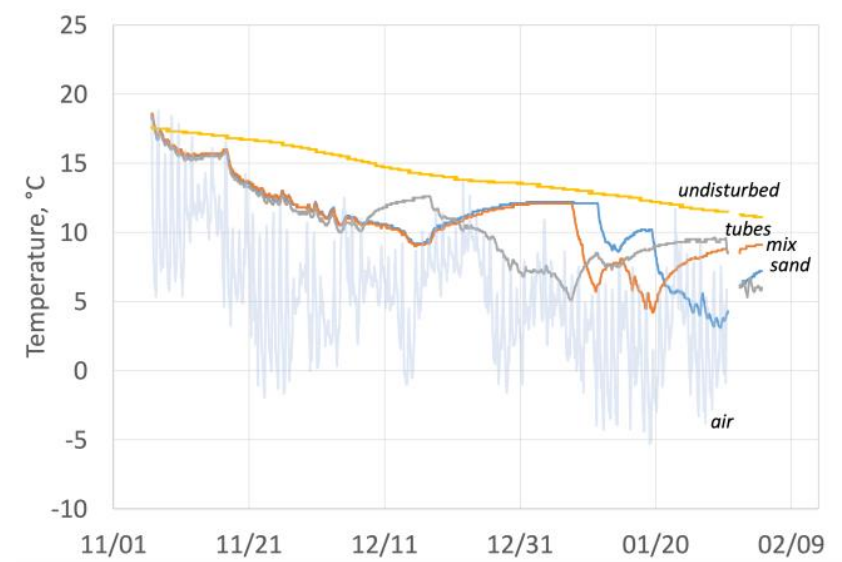

(a) Soil temperature $1.7 \mathrm{~m}$ deep and $0.2 \mathrm{~m}$ far from the flat panel for the three series of ground heat exchangers

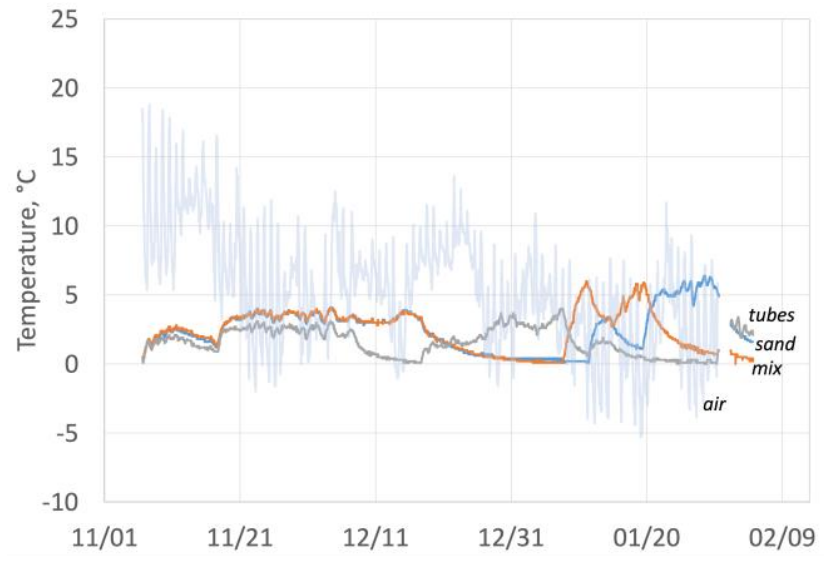

(b) Soil temperature difference between sensors placed $0.2 \mathrm{~m}$

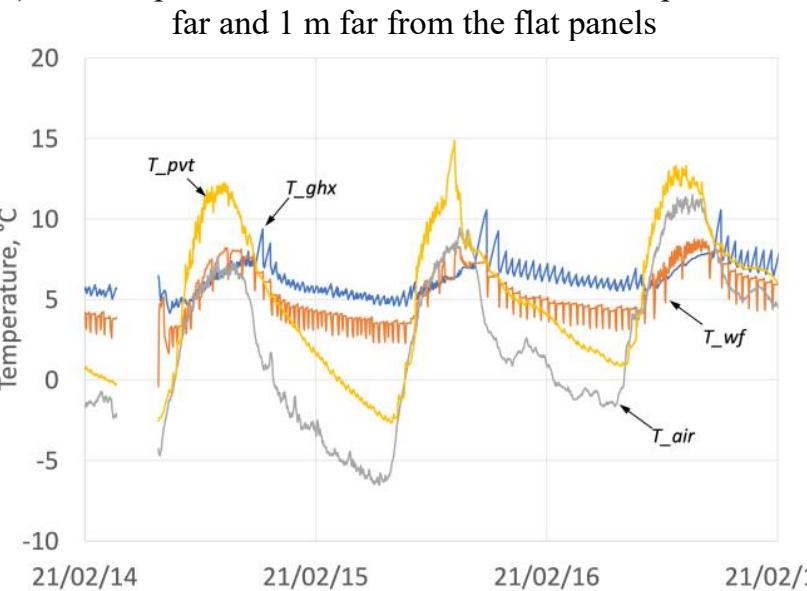

(c) Air, PV/T outlet, flat-panel outlet, and source buffer tank

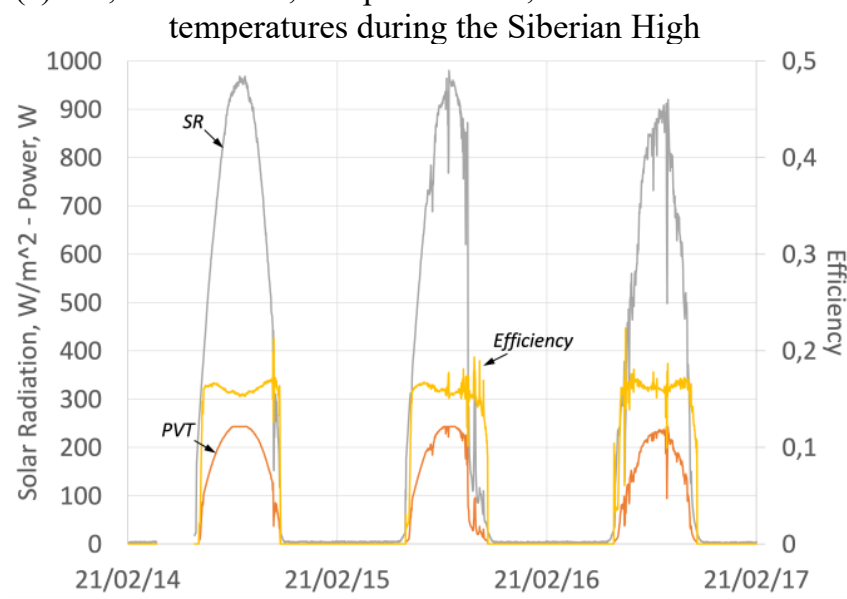

(d) Solar irradiation during the Siberian High.

Figure 10. Winter season: preliminary experimental results

\section{CONCLUSIONS}

The state-of-the-art of the IDEAS research project has been presented. The project proposes a novel heat pump-driven multi-source RES for the building climatisation. Sun, air, and ground are exploited as thermal sources, and attention is given to the issue of thermal energy storage by a diffuse adoption of PCMs in several components throughout the system.

The set-up of a small-scale plant implementing the proposed solution and used as a test facility has been discussed. Preliminary results for the summer and the winter season have been collected and were presented. 
While results over a broader span of time are still needed in order to draw more precise and quantitative conclusions on the effectiveness of the system, something can still be speculated on the basis of the available data. The use of multiple renewable energy sources appears a promising solution in that it allows the heat pump to be fed by the source granting the most advantageous temperature jump at any time.

Yearly, over the seasons, such a system would take a great advantage from an adequate thermal energy storage, which yet is difficult to be obtained. The change in the thermal inertia brought by the PCM in the radiant floor, in the ground, and in the PV/T cooling tank is of the order of the tens of $\mathrm{MJ}$ and, while perceivable, still appears of modest entity compared to the large quantities of heat that can be exchanged by such a system, for instance, over a season.

The project highlights how the use of renewable resources on a building scale is a way to be pursued but must be combined with appropriate thermal storage capacity whose feasibility becomes actually complex on an urban scale.

\section{ACKNOWLEDGMENT}

This project has received funding from the European Union's Horizon 2020 research and innovation programme under grant agreement No 815271.

\section{REFERENCES}

[1] Energy in Ireland 1990-2015. (2016). Sustainable Energy Authority of Ireland, Dublin, Ireland.

[2] Tracking Clean Energy Progress. (2017). International Energy Agency, Paris, France.

[3] Energy Roadmap 2050. (2012). European Commission, Luxembourg, Luxembourg.

[4] EPHOCELL. Smart Light Collecting System for the Efficiency Enhancement of Solar Cells. https://cordis.europa.eu/project/id/227127, accessed on Feb. 2021.

[5] PEDAL. Plasmonic Enhancement \& Directionality of Emission for Advanced Luminescent Solar Devices. https://cordis.europa.eu/project/id/639760, accessed on Feb. 2021.

[6] TRI-HP. Trigeneration Systems Based on Heat Pumps with Natural Refrigerants and Multiple Renewable Sources. https://www.tri-hp.eu, accessed on Feb. 2021

[7] Hybrid BioVGE. Hybrid Variable Geometry Ejector Cooling and Heating System for Buildings Driven by Solar and Biomass Heat. https:/hybridbiovge.inegi.up.pt, accessed on Feb. 2021.

[8] SolBioRev. Solar-Biomass Reversible Energy System for Covering a Large Share of Energy Needs in Buildings. http://www.solbiorev.eu, accessed on Feb. 2021.

[9] GEO4CIVHIC. Most Easy, Efficient and Low Cost Geothermal Systems for Retrofitting Civil and Historical Buildings. https://geo4civhic.eu, accessed on Feb. 2021.

[10] MAKING-CITY. Making City. http://makingcity.eu, accessed on Feb. 2021.

[11] RE-Cognition. Renewable, Cogeneration and Storage Technologies Integration for Energy Autonomous Buildings. https://re-cognition-project.eu, accessed on Feb. 2021

[12] RES4BUILD. Renewables for Clean Energy Buildings in a Future Power System. https://res4build.eu, accessed on Feb. 2021.

[13] i-STUTE. Interdisciplinary Centre for Storage, Transformation and Upgrading of Thermal Energy. https://www.i-stute.org, accessed on Feb. 2021.

[14] INPATH TES. PhD on Innovation Pathways for Thermal Energy Storage. https://www.inpathtes.eu/about-us/, accessed on Feb. 2021

[15] SWS-Heating. SWS Heating. http://www.swsheating.eu, accessed on Feb. 2021.

[16] TESSe2b. Thermal Energy Storage Systems for Energy Efficient Buildings. http://www.tesse2b.eu, accessed on Feb. 2021.

[17] NPMSSES. Nanoparticle Enhanced Molten Salts for Solar Energy Storage. https://cordis.europa.eu/project/id/706788/it, accessed on Feb. 2021.

[18] EffiBUILDING. Thermal Energy Storage with Phase Change Materials for Energy Efficiency of European Building Stock. https://www.effibuilding.eu, accessed on Feb. 2021.

[19] Carlini, M., McCormack, S.J., Castellucci, S., Ortega, A., Rotondo, M., Mennuni, A. (2020). Modelling and numerical simulation for an innovative compound solar concentrator: Thermal analysis by FEM approach. Energies, $13(3)$ : 548. https://doi.org/10.3390/en13030548

[20] Devanarayanan, K., Kalidasa Murugavel, K. (2014). Integrated collector storage solar water heater with compound parabolic concentrator-development and progress. Renewable and Sustainable Energy Reviews, 39: 51-64. https://doi.org/10.1016/j.rser.2014.07.076

[21] Ahmed, H., McCormack, S.J., Doran, J. (2017). Plasmonic luminescent down shifting layers for the enhancement of CdTe mini-modules performance. Solar Energy, 141: 242-248. https://doi.org/10.1016/j.solener.2016.11.036

[22] Hovel, H.J., Hodgson, R.T., Woodall, J.M. (1979). The effect of fluorescent wavelength shifting on solar cell spectral response. Solar Energy Materials, 2(1): 19-29. https://doi.org/10.1016/0165-1633(79)90027-3

[23] Bottarelli, M., Bortoloni, M., Su, Y., Yousif, C., Aydin, A.A., Georgiev, A. (2015). Numerical analysis of a novel ground heat exchanger coupled with phase change materials. Applied Thermal Engineering, 88: 369-375. https://doi.org/10.1016/j.applthermaleng.2014.10.016

[24] Pulat, E., Coskun, S., Unlu, K., Yamankaradeniz, N. (2009). Experimental study of horizontal ground source heat pump performance for mild climate in Turkey. Energy, 34: 1284-1295. https://doi.org/10.1016/j.energy.2009.05.001

[25] Liu, C., Zhao, H., Liu, H. (2020). Development of an experimental platform for multi-source complementary heat pump heating system. International Journal of Heat and Technology, 38(2): 321-326. https://doi.org/10.18280/ijht.380206

[26] Catalina, T., Virgone, J., Blanco, E. (2011). Multi-source energy systems analysis using a multi-criteria decision aid methodology. Renewable Energy, 36: 2245-2252. https://doi.org/10.1016/j.renene.2011.01.011

[27] Fleming, E., Wen, S., Shi, L., da Silva, A.K. (2015). Experimental and theoretical analysis of an aluminum foam enhanced phase change thermal storage unit. International Journal of Heat and Mass Transfer, 82: 273- 
281.

https://doi.org/10.1016/j.ijheatmasstransfer.2014.11.022

[28] Bottarelli, M., Bortoloni, M., Su, Y. (2015). Heat transfer analysis of underground thermal energy storage in shallow trenches filled with encapsulated phase change materials. Applied Thermal Engineering, 90: 1044-1051. https://doi.org/10.1016/j.applthermaleng.2015.04.002

[29] Ansuini, R., Larghetti, R., Giretti, A., Lemma, M. (2011). Radiant floors integrated with PCM for indoor temperature control. Energy and Buildings, 43(11): 3019-3026. https://doi.org/10.1016/j.enbuild.2011.07.018

[30] Akbari, H., Browne, M.C., Ortega, A., Huang, M.J., Hewitt, N.J., Norton, B., McCormack, S.J. (2019). Efficient energy storage technologies for photovoltaic systems. Solar Energy, 192: 144-168. https://doi.org/10.1016/j.solener.2018.03.052

[31] Ciriello, V., Bottarelli, M., Di Federico, V., Tartakovsky, D.M. (2015). Temperature fields induced by geothermal devices. $\quad$ Energy, 93: 1896-1903. http://dx.doi.org/10.1016/j.energy.2015.10.052 